\title{
Research Paper \\ Investigation of Microbial Contamination and Physicochemical Properties of Compounded Medications in Pharmacies
}

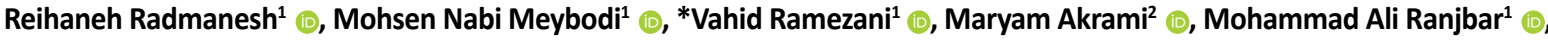 \\ Azadeh Emami ${ }^{1}$ (C)
}

1. Department of Pharmaceutics, Faculty of Pharmacy, Shahid Sadoughi University of Medical Sciences, Yazd, Iran.

2. Department of Psychiatry Research Center of Addiction and Behavioral Sciences, Shahid Sadoughi University of Medical Sciences, Yazd, Iran.

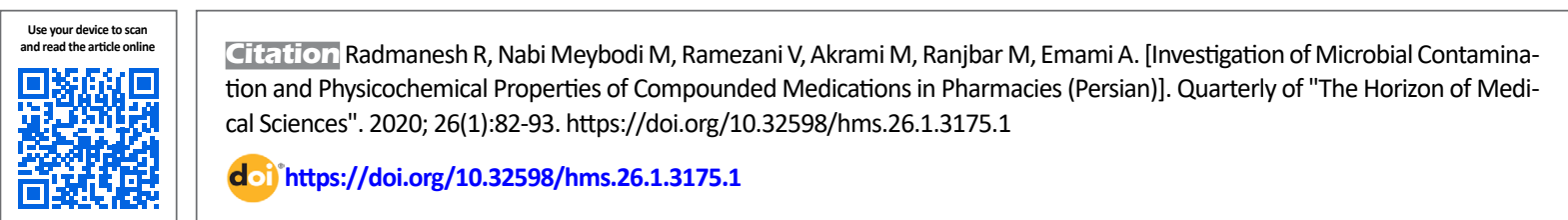

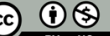

Received: 08 Jul 2019

Accepted: 15 Dec 2019

Available Online: 01 Jan 2020

Key words:

Compounded medications, Pharmacy, Microbial contamination

\section{A B S T R A C T}

Any pharmaceutical product made in pharmacy, hospital or factory may be contaminated with microbes. This contamination can originate from raw materials or during production. Hence, it is important to study the physical and chemical properties and stability of compounded drugs.

Methods \& Materials In this study, first a specific sample of prescribed medication was ordered from 63 pharmacies in Yazd, Iran. After collecting the samples, the amount of microbial contamination, viscosity and particle size distribution and their stability were investigated and their results were compared to the standard levels.

Findings Based on the results, $31.7 \%$ of the samples had discoloration and $23.8 \%$ showed creaming phenomenon. In terms of particle size distribution, $57.1 \%$ of the samples had a $20-40 \mu \mathrm{m}$ particle size and $49.2 \%$ had a viscosity equal to $2500-3000$ centipoise. Regarding stability, $12.6 \%$ of the samples underwnet phase change at $30-40^{\circ} \mathrm{C}$. About of the amount of hydroquinone in samples, $35 \%$ had acceptable amount. In $23.8 \%$ of the samples, fungal infection was observed.

Conclusion Contrary to a popular belief that the compounded medicines produced in pharmacies have microbial contamination, the results of this study showed that the microbial contamination of these compounded medications is low.

\section{Extended Abstract}

\section{Introduction}

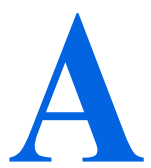

ny compounded form of pharmaceutical product made in pharmacies, hospital or factory may be contaminated with microbes. This contamination can originate from raw materials or during production. Hence, it is important to study the physical and chemical properties and stability of compounded drugs. Microbial contamination of compounded and health products has been considered from the past and for this reason, in pharmaceutical pharmacopoeias, some restrictions have been put on such products. For such specific products, it is necessary that they be free of contaminating microorganisms [3]. Small drug particles in semi-solid form of pharmaceutical compounds may dissolve in the continuous phase and join larger particles (e.g. Ostwald ripening). To examine the tendency of Ostwald ripening during the production stage, it is possible to study the room temperature cycle up to $40^{\circ} \mathrm{C}$. [9].

\section{* Corresponding Author:}

Vahid Ramezani, PhD.

Address: Department of Pharmaceutics, Faculty of Pharmacy, Shahid Sadoughi University of Medical Sciences, Yazd, Iran.

Tel: +98 (912) 8015038

E-mail: vramezani@razi.tums.ac.ir 
The particle size of compounded products is affected by the viscosity and concentration of their ingredients [10]. The $\mathrm{pH}$ of a semi-solid form may be related to multiple failure modes in the drug product. The $\mathrm{pH}$ effect of topical drug forms in the living organism (in vivo) on the skin is not well known [11]. One of the goals of quality assurance programs is to establish systems that can ensure the uniformity of the properties of medications in all doses or packages, and on the other hand, to ensure their safety when consumed. The assurance about uniformity (effectiveness) and health of the medications are related to the stability of the compounded product.

Therefore, it is important to pay attention to the stability and properties of these products. In this regard, various tests have been performed to evaluate the efficacy and safety of dermatological drugs, including assessment of the amount of active ingredients in the formulation, the uniformity of dosage forms, $\mathrm{pH}$, the amount of water content, microbial constraints, viscosity and particle size [2]. Due to the importance of physicochemical and microbial properties of the compounded medications produced in urban pharmacies, this study aimed to investigate their physicochemical properties and microbial contamination.

\section{Methods and Materials}

This is an experimental field study. 63 prescribed compounded medications with specific formulation (Table 1) containing an oxidizing substance (hydroquinone), a substance with the ability to change the $\mathrm{pH}$ of the product (salicylic acid), and an antioxidant (vitamin C) were collected from 63 pharmacies in Yazd city in the spring 2017, and experimental studies on the study variables continued until the fall 2017. According to Pharmacopoeia guidelines, the numbers of microbes including Pseudomonas aeruginosa,

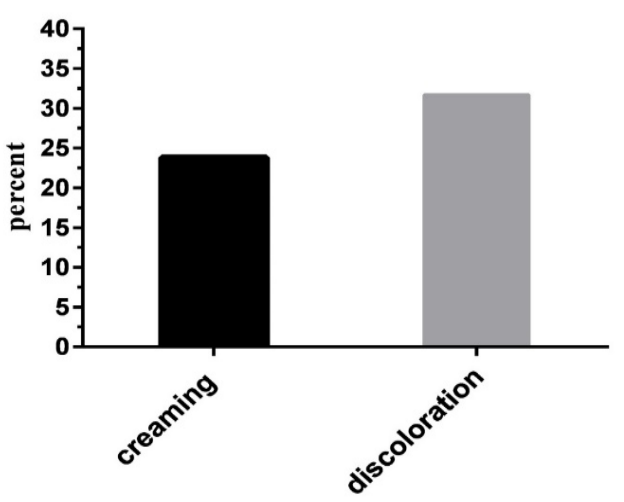

Quarterly of

The Horizon of Medical Sciences

Figure 1. Microbial contamination of semi-solid pharmaceutical products made in the pharmacies of Yazd City
Staphylococcus aureus, Candida sp., and Escherichia coli that are not allowed in topical drugs were counted using the spread plate technique.

To measure the viscosity, 1 gram of each sample was placed in the viscometer (Brookfield, USA) at room temperature and then, it was measured at $10 \mathrm{rpm}$. In order to test the physicochemical properties of the samples, one gram of each sample was poured into a 10-cc beaker and placed on a heater, using a magnet to create a uniform flow and increase the temperature. In the end, the temperature at which the samples underwent phase change was measured using a thermometer. The amount of hydroquinone in each sample was measured in milligrams per gram of cream with a spectrophotometer at a wavelength of $293 \mathrm{~nm}$ where methanol was used as a blank.

\section{Results}

According to Table 2, only one sample contaminated with Staphylococcus aureus was found, and microbial contamination by Pseudomonas aeruginosa and Escherichia coli did not occur outside the designated range, and 15 samples had fungal infection (candida albicans) (Figure 1). One month after the samples were stored in ideal conditions, $22.2 \%$ of them showed discoloration. After a few weeks, $31.7 \%$ had discoloration and $23.8 \%$ showed creaming phenomenon (Figure 2 ).

In terms of particle size distribution, $22.2 \%$ of the samples had a 10-20 $\mu \mathrm{m}$ particle size, $33.3 \%, 20-30 \mu \mathrm{m} ; 23.8 \%$, 30$40 \mu \mathrm{m} ; 12.6 \%, 40-50 \mu \mathrm{m}$; and $7.9 \%$ were in a range of 50 $60 \mu \mathrm{m}$. Moreover, $12.6 \%$ of the samples underwent phase change and creaming at a temperature of $30-40^{\circ} \mathrm{C}, 77.7 \%$ at $40-50^{\circ} \mathrm{C}$, and $9.5 \%$ at $50-60^{\circ} \mathrm{C}$. The maximum viscosity

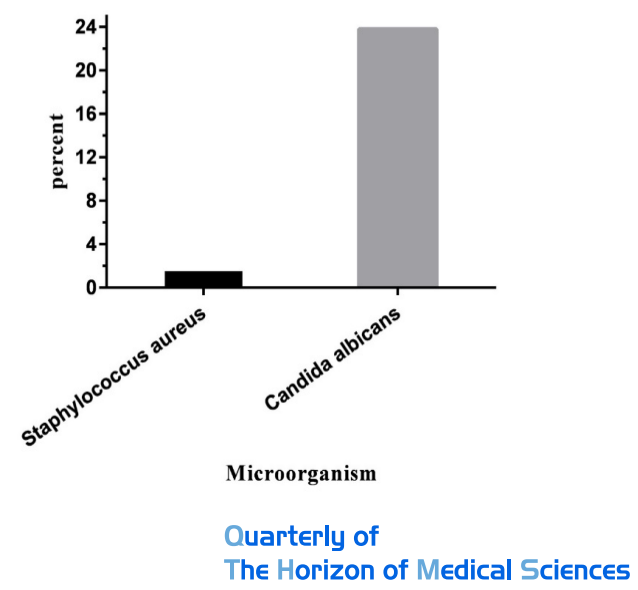

Figure 2. The percentage of creaming and discoloration in the semi-solid pharmaceutical products made in the pharmacies of Yazd City 
Table 1. The ordered drug formulation for the study

\begin{tabular}{cc}
\hline Ingredients & Amount \\
\hline Hydroquinone & $1 \mathrm{~g}$ \\
\hline Salicylic acid & $1 \mathrm{~g}$ \\
Vitamin C & $1 \mathrm{~g}$ \\
\hline Cold cream & $10 \mathrm{~g}$ \\
\hline & $\begin{array}{l}\text { Quarterly of } \\
\text { The Horizon of Medical Sciences }\end{array}$
\end{tabular}

Table 2. Acceptance criteria for nonsterile pharmaceutical products according to the US Pharmacopoeia

\begin{tabular}{|c|c|c|c|}
\hline Specified & $\begin{array}{l}\text { Total Combined } \\
\text { Yeasts/Molds Count } \\
\text { (cfu/g or cfu/ml) }\end{array}$ & $\begin{array}{c}\text { Total Aerobic } \\
\text { Microbial Count } \\
\text { (Cfu/g or cfu/ml) }\end{array}$ & $\begin{array}{c}\text { Route of } \\
\text { Addministration }\end{array}$ \\
\hline $\begin{array}{l}\text { Absence of } \\
\text { Pseudomonas or } \\
\text { Staphylococcus }\end{array}$ & & & Transdermal patches \\
\hline
\end{tabular}

of the semi-solid product was between 2,500 and 3,000 centipoise (29 samples). Hydroquinone in $50 \%$ of the samples was more than one gram; in $35 \%$, between 0.9 and $1 \mathrm{~g}$, and in $15 \%$ it was less than $0.9 \mathrm{~g}$.

\section{Discussion}

Elmorsy and Hafez [12] in a study on various cosmetic brands found bacterial and fungal-microbial contamination in $22.6 \%$ of the samples. The products were contaminated with pseudomonas aeruginosa, Staphylococcus aureus, and Escherichia coli. In study conducted in Poland by Glogowski et al. [19] on the viscosity of salicylic acid and boric acid inside the ointment formulation, they concluded that the formulation containing salicylic acid had better viscosity. Kumar et al [21] in a study to determine the amount of lidocaine in the ointment formulation by spectrophotometer at a wavelength of $263 \mathrm{~nm}$, found that its amount was $98.7 \%$. Jeon et al. [11] found out that changing the $\mathrm{pH}$ of any topical cream could influence the effect of the cream on the skin and its other features.

\section{Conclusion}

One of the limitations of this study was the lack of uniform conditions in pharmacies for making the study drugs. According to the results obtained from particle size and physicochemical properties, the related principles during the production of compounded medications should be observed more. Numerous factors such as increased awareness, adherence to principles, more use of preservatives, use of moisturizing creams (which contain significant preservatives) and use of alcohol as a solvent in the study samples, can reduce the rate of contamination in compounded drugs made in pharmacies.

\section{Ethical Considerations}

\section{Compliance with ethical guidelines}

This study considered all the rules related to pharmaceutical research and obtained an ethical approval (Code: IR.SSU. MEDICINE.REC.1396.85) from the Medical University of Yazd.

\section{Funding}

This study received financial support from the Deputy for Research of Shahid Sadoughi University of Medical Sciences.

\section{Authors' contributions}

All authors contributed in preparing this article.

\section{Conflicts of interest}

The authors declared no conflict of interest.

\section{Acknowledgements}

The authors would like to thank Dr. Masoud Heidarinejhad and all those had cooperation in conducting this study. 


\title{
بررسى خصوصيات فيزيكوشيميايى و آلودَّى ميكروبى داروهاى تركيبى داروخانهانى شهر يزد
}

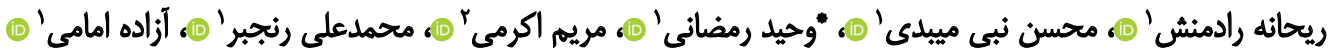

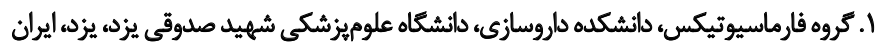

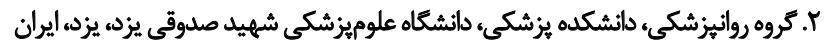

\begin{abstract}
حكSد

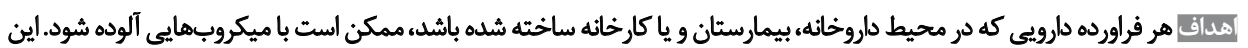

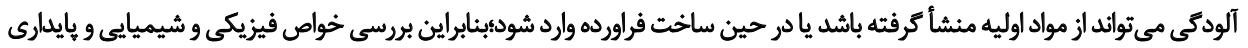

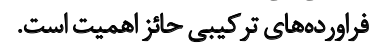

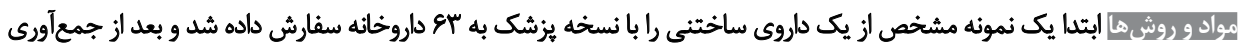

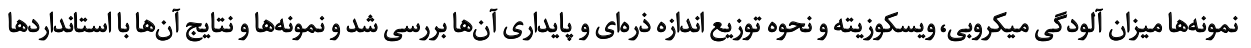
تطبيق داده شد.

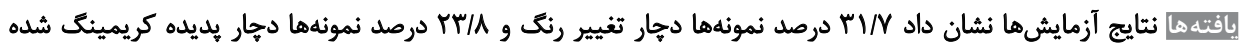

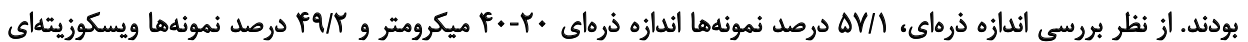

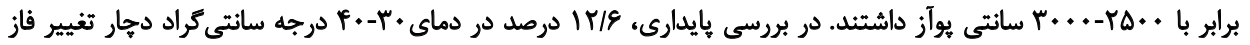

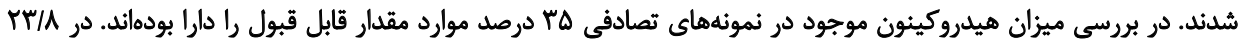

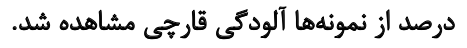

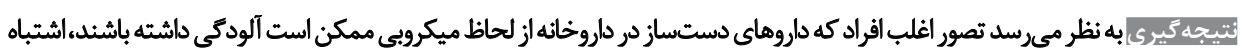

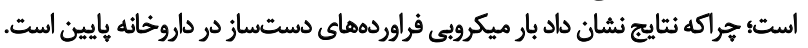

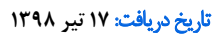

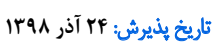
تاريخ انتشار: الدى

كاريدوارٔها:

مقدمه

كاربرد ساليسيليك اسيد ينج درصد به عنوان كراتوليتيك و همجنين

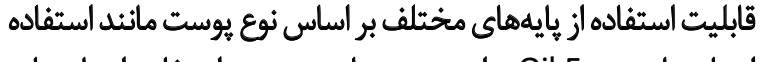

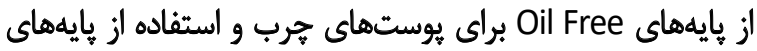

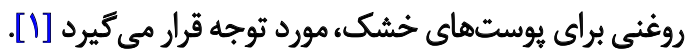

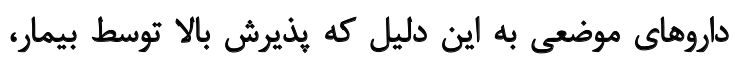

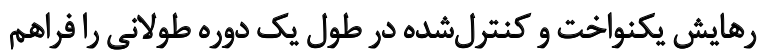

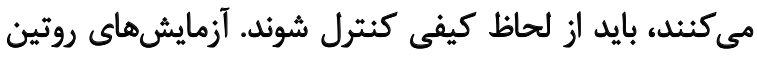

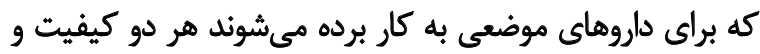

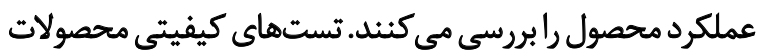

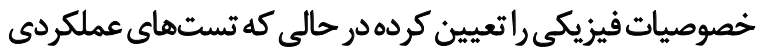

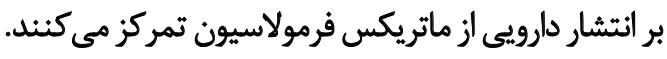

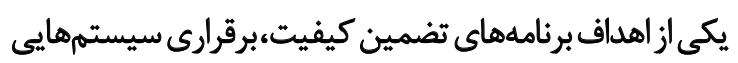

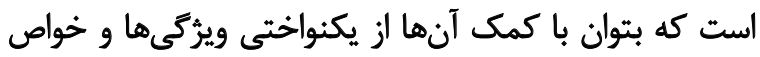

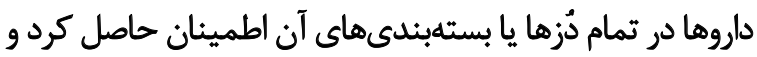

على غعم تهيه و عرضه اقلام دارويى اساسى مورد نياز بيماران

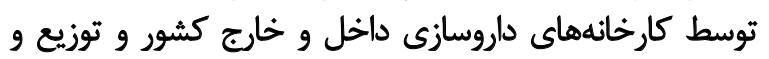

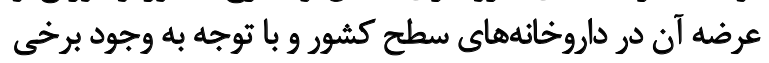

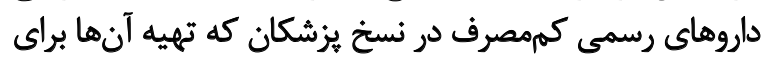

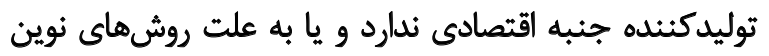

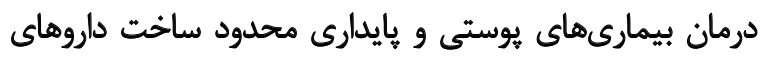

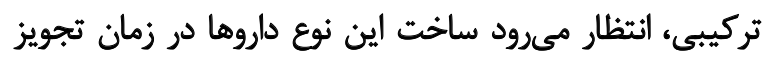

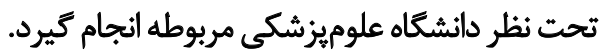

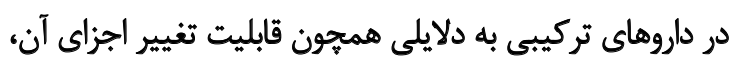

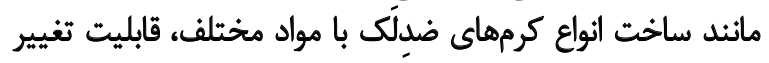

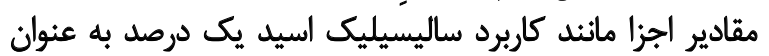

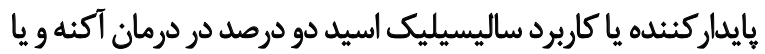




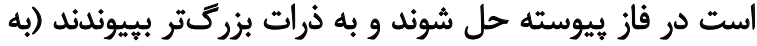
عنوان مثال رسيدن به به بهاز

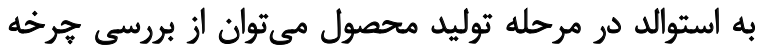

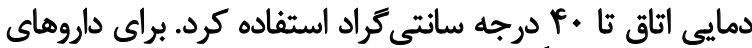

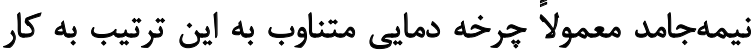

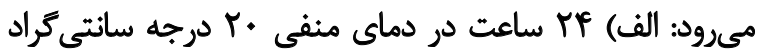

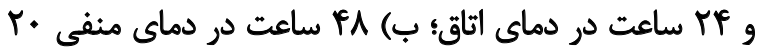

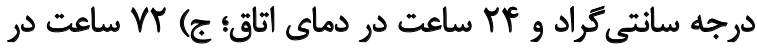

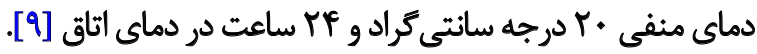
اندازه ذرات محصولات دارويى تحت تأثير ويسكوزيته و غلظت

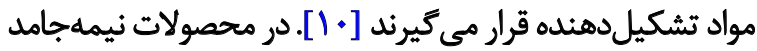

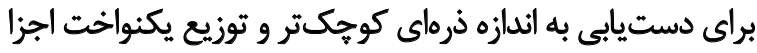

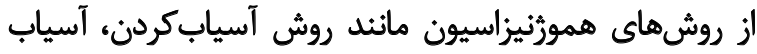

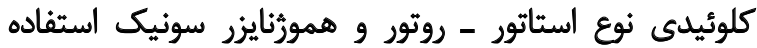

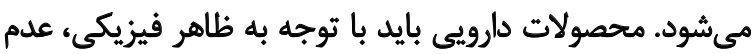

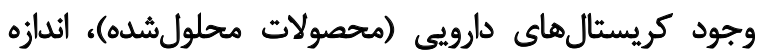

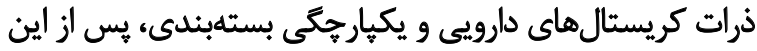
سيكلها يايدار باقى بمانند [9].

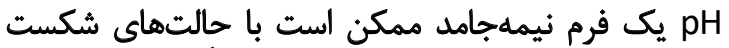

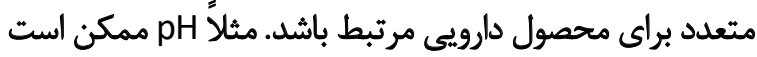

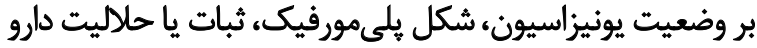

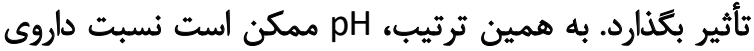

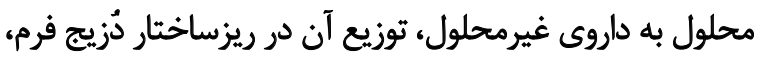

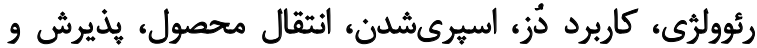

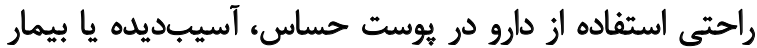

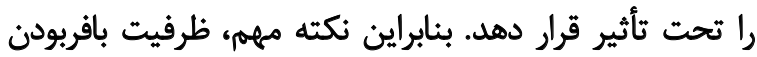

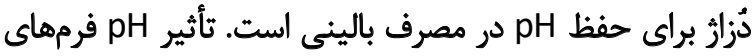

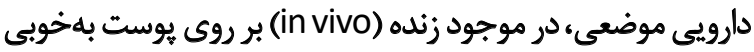

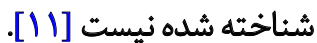

اصلاح ويسكوزيته قسمت مهمى از فرمولاسيون نيمهجامد

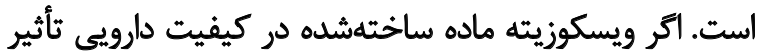

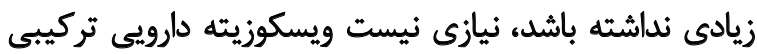

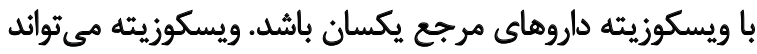

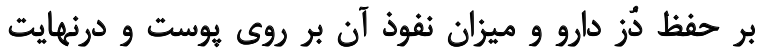

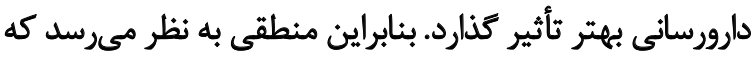

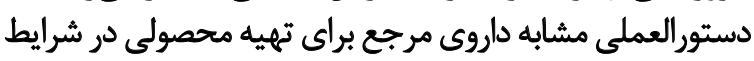

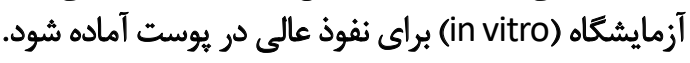

علاوه بر اين نياز است كه ويرگكىهاى ماندكارى بر روى يوست

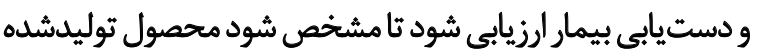

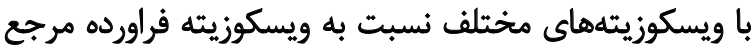

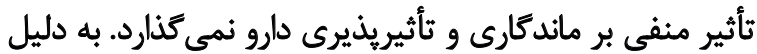

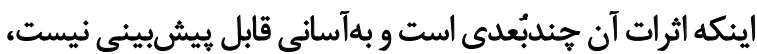

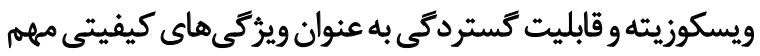

از طرفى بتوان از بىضرر بودن دارو موقع مصرف آن مطمئن بود.

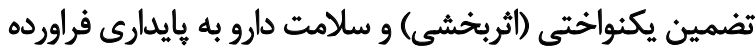

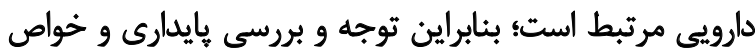

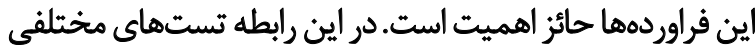

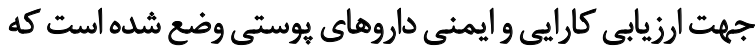

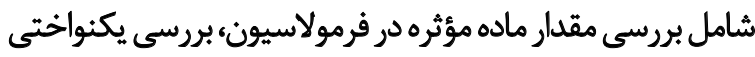

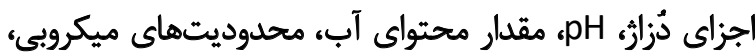

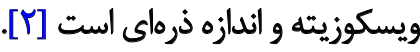

آلودكى ميكروبى فراوردههاى دارويى و بهداشتى از كذُشته

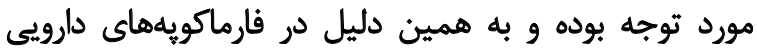

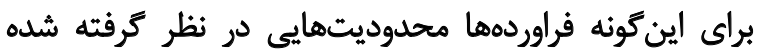

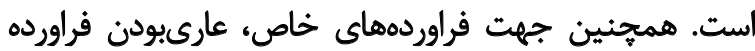

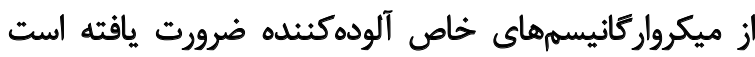

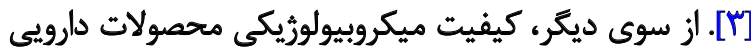

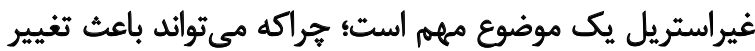

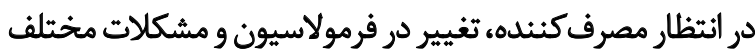

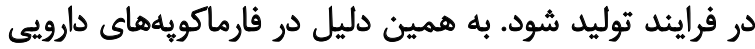

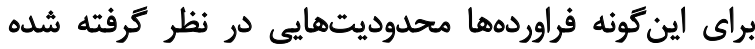

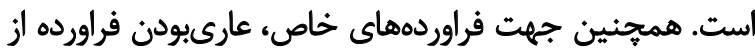

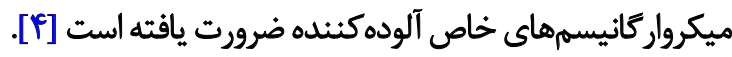
فراوردهاى آرايشى و بهداشتى موضعى (كرمها و يمادهاي

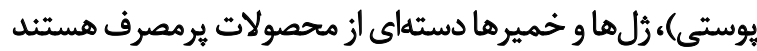

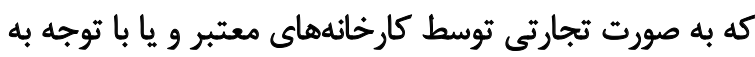

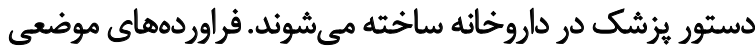

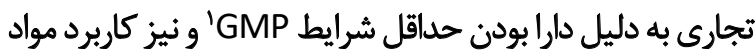

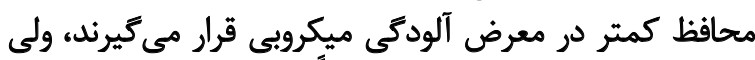

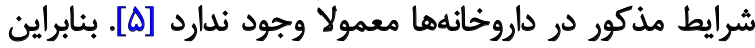

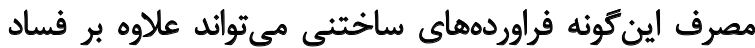

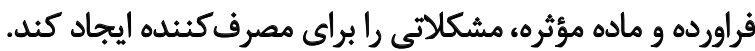

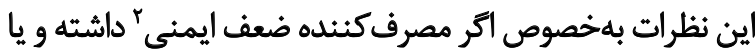

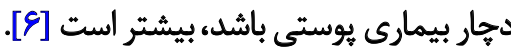

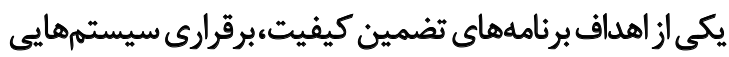

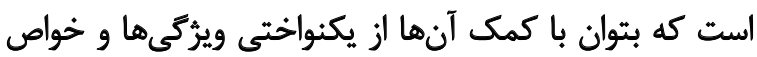

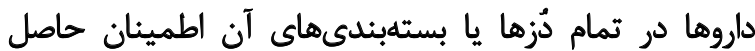

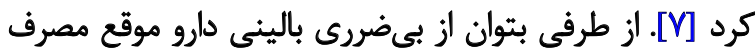

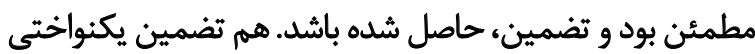

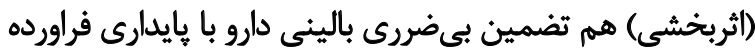

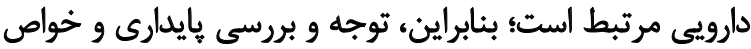

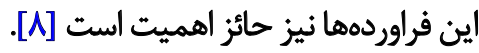
ذرات كوجك دارويى در فرم نيمهجامد تركيبات دارويى ممكن

1. Good Manufacturing Practice 2. Immunocom Promised 
جهت تشخيص افتراقى ميكرواركانيسمهاى ممنوعه شامل

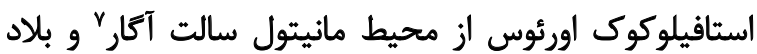

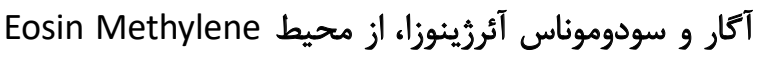

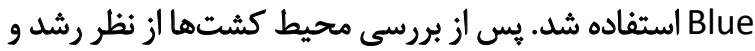

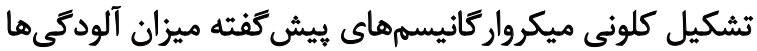
مشَخص شد.

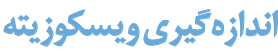

براى اندازهيرى ويسكوزيته مقدار يك ترم از نمونه موردنظر

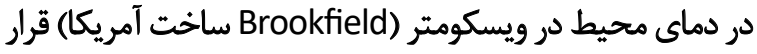

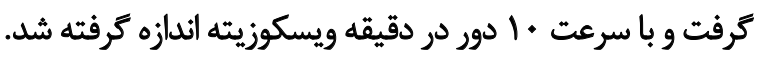

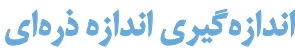

در مورد اندازه ذرهاى نمونهها نيز مقدار يك كرم از آنها در

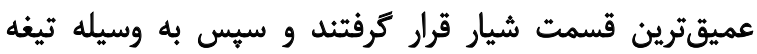

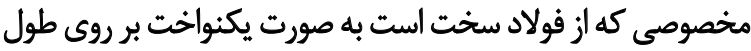

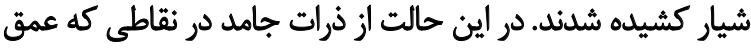

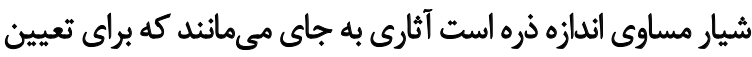

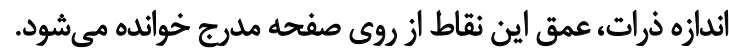

\section{بروسي حُصوصيات فيزيكو شيميايق}

آزمايشات ارزيابى فيزيكوشيميايي نمونهها شامل بررسى يري

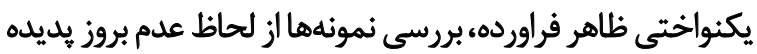

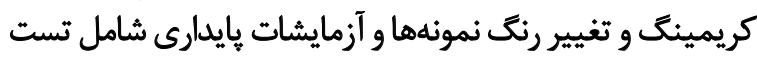

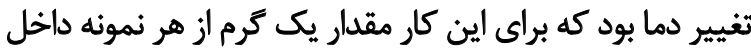

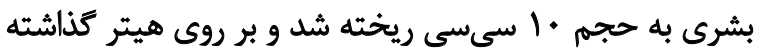

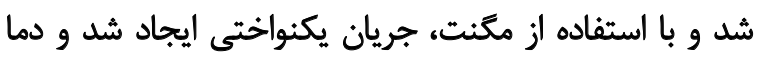

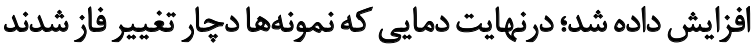
با بتفاده از دماسنج اندازمخيرى شد.

$$
\text { تعيين مقدار ماده مؤثره }
$$

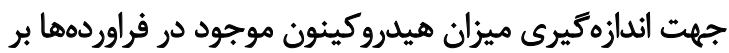

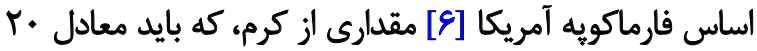

7. Mannitol salt agar
در مراحل اوليه توليد محصول در نظر كرفته مىشوند [9]

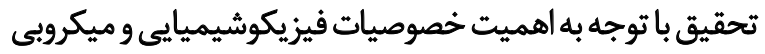

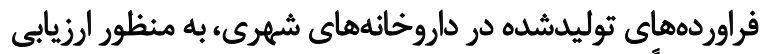

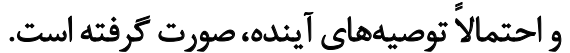

مواد ورش روشا

در اين مطالعه بـ داروى تركيبى با فرمولاسيون مشخص (جدول

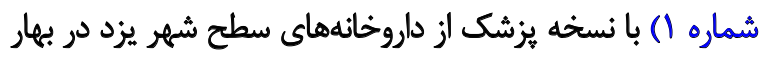

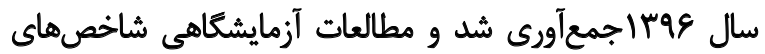

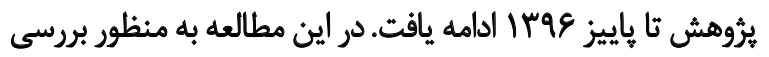

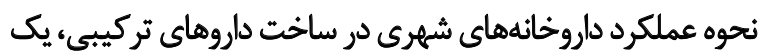

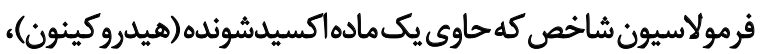

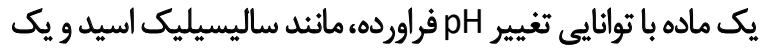

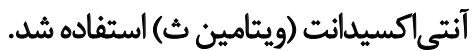

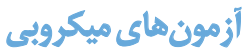

با توجه به ضوابط فارماكويه ميزان شمارش ميكروبى و خواص

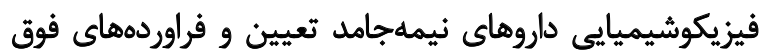

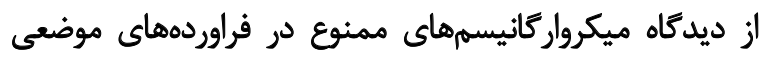

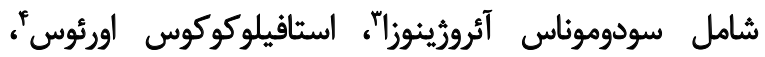

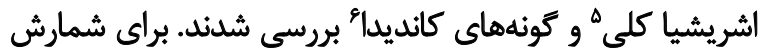

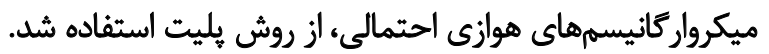

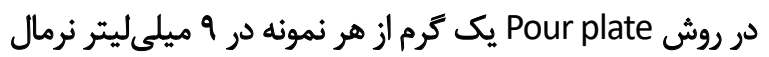

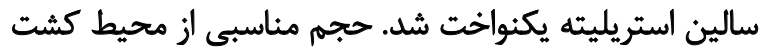

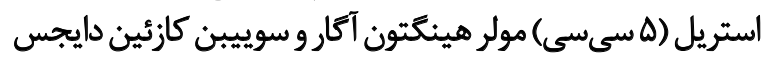

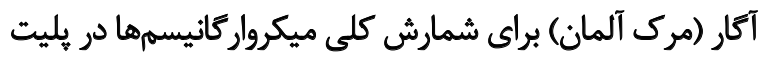

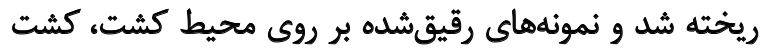

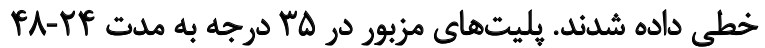

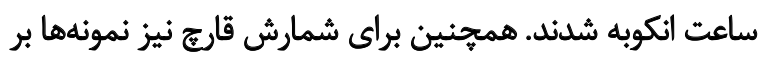
روى محيط استريل سابرو دكستروز آتار (مرك آلمان) كشت دارئ داده نداه

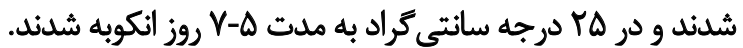

3. Pseudomonas aeruginosa

4. Staphylococcus aureus

5. Escherichia coli

6. Candida sp

جدول ا. فرمولاسيون نمونه تركيبى درخواستى

تركيبات

Hydroquinon

Salicylic acid

Vitamin c

Cold cream

\section{مقدار,}

ist

(2)

(5)

1.

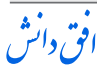


تنها يك نمونه آلوده به استافيلوكوك اورئوس يافت شد وآلودئى

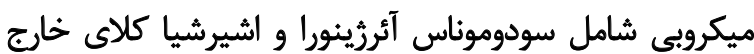

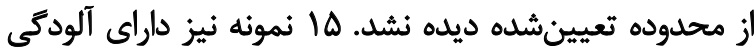

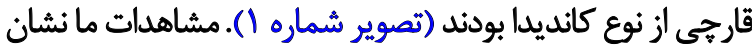

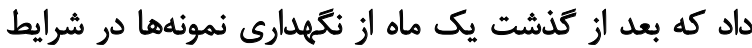

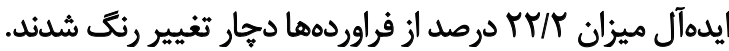
بررسى فراورده از لحاظ عدم يديده كريمينگ (به اين مفهوم

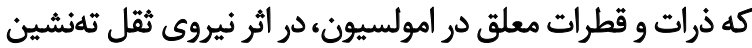

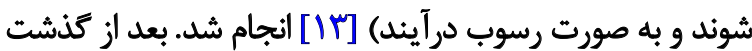

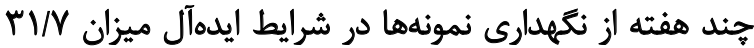

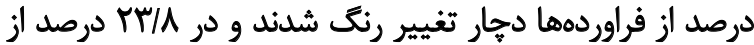
فراوردهها يديده كريمينگ مشاهده شد (تصوير شماره ب).

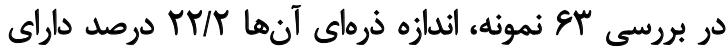

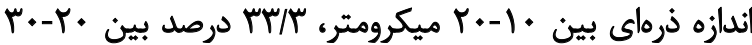

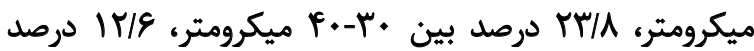

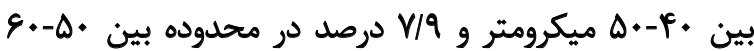
ميكرومتر بودند (تصوير شماره ب). در برسى بايدارى بو نمونه در تغييرات دمايى و دو فاز شدن

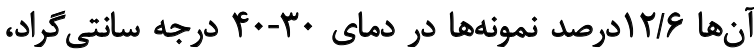

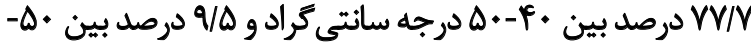

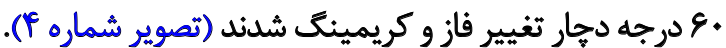
در اندازهكيرى ويسكوزيته توسط دستكاه ويسكومتر بيشترين

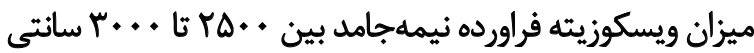

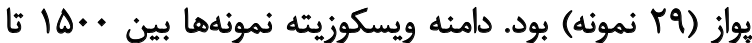

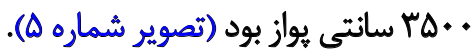
در بررسى ميزان هيدروكينون، ·r نمونه به صورت تصادفى در

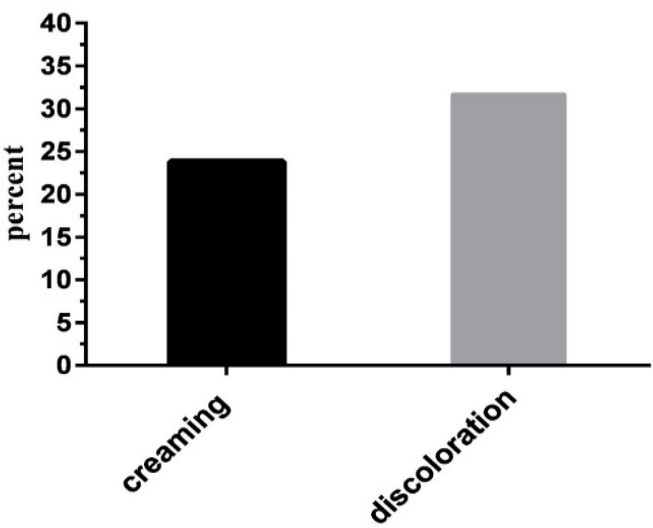

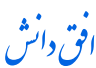

تصوير r. نمودار وضعيت نمونهها از لحاظ وجود بإيد كريمينكّ و تغيير رنت

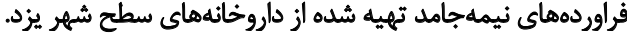

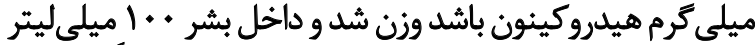

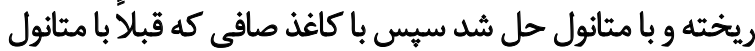

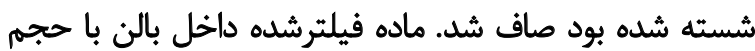

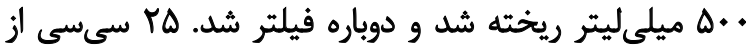

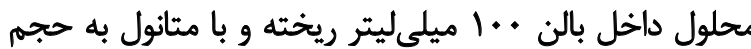

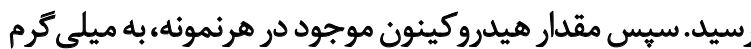

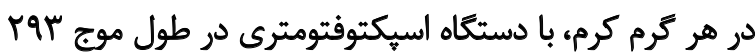

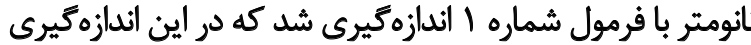

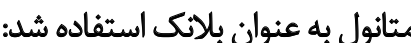

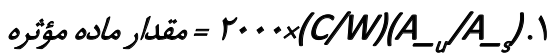
ن غ غلظت بر اساس USP كه يك ميلى كرم بر ميلىليتر در

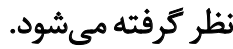

$$
\begin{aligned}
& \text { = وزن كرم مصرفى بر اساس كرم } \\
& \text { Au = جذب ماده مورد بررسى } \\
& \text { As= جذب ماده استاندارد (مثانول) }
\end{aligned}
$$

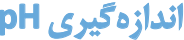

براى سنجش pH نيز با استفاده از كاغذ تورنسل و بررسى رنك

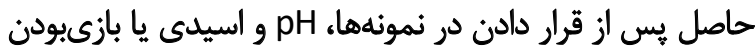

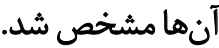
يافتلها

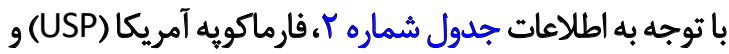

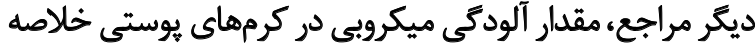

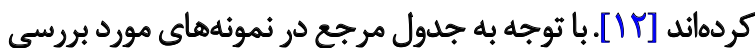

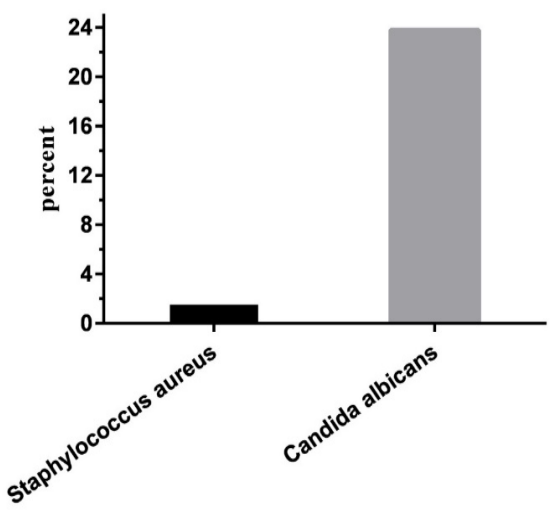

Microorganism

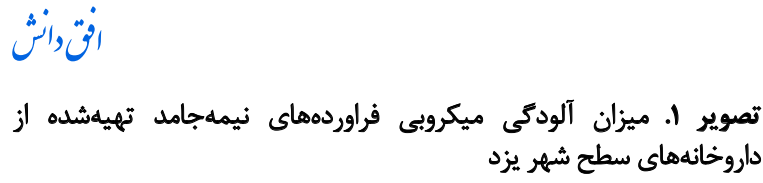




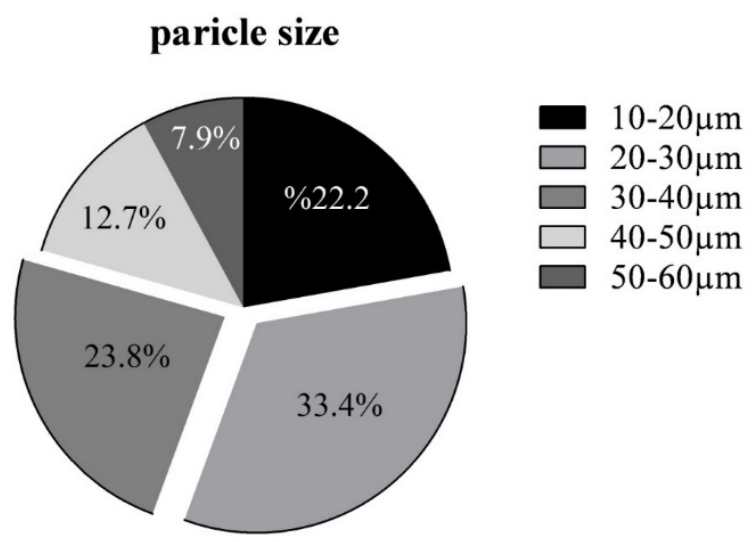

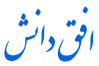

تصوير س. بررسى اندازه ذرهاى فراوردهماى نيمهجامد تهيهشده از داروخانههاى سطح شهر يزد

مواردى است كه در داروهاى جالينوسى بايد مدنظر قرار كيرد.

آلودگى ميكروبى در فراورده مى تواند باعث از بين بردن يايداري

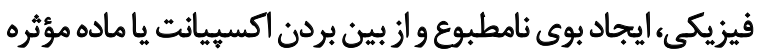

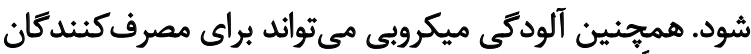

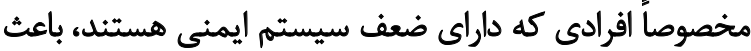

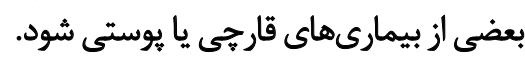

يُروهشهاى انجامشده توسط المورسى و حافظ بر روى برندهاى

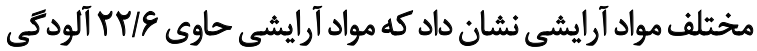

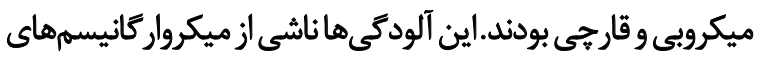

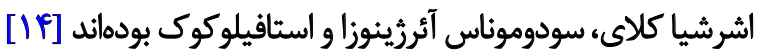

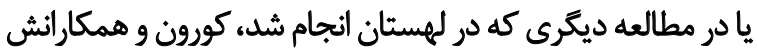

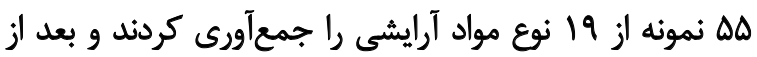

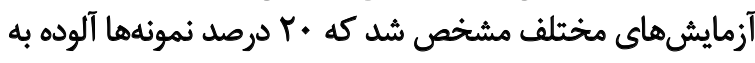

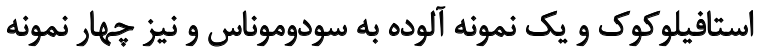

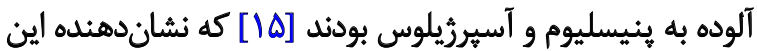

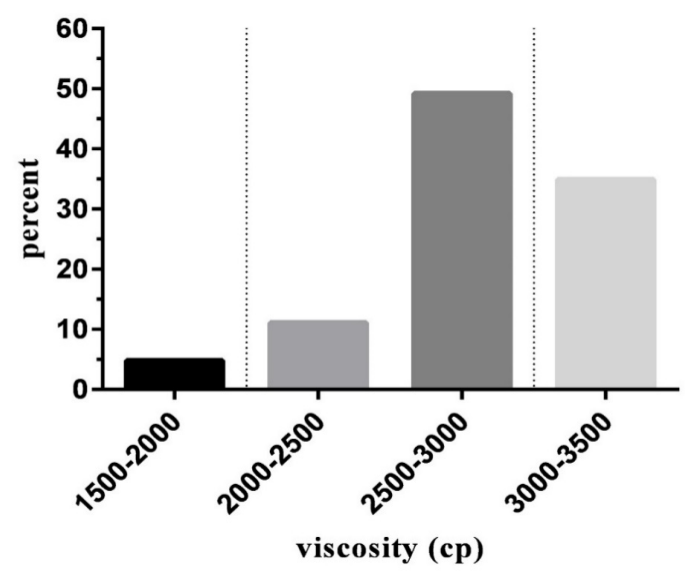

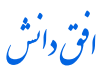

تصوير هـ توزيع فرواني ميزان ويسكوزيته فراوردهاي نيمهامدامد تهيهشده از داروخائهاي سطح شهر يزئ نوريز
طول موج كوج نانومتر ارزيابى شدند.نتايج نشان داد هيدروكينون

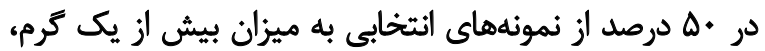

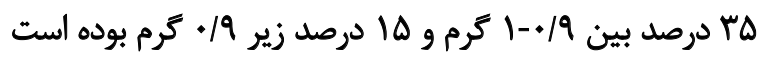

$$
\text { (تصوير شماره (9). }
$$

با توجه به اينكه در فرمول خواستهشده، مواد به صورت يودرى

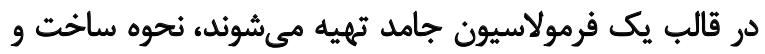

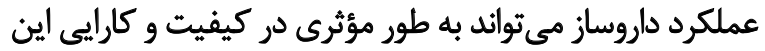

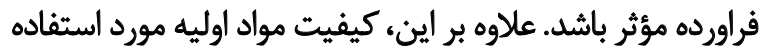

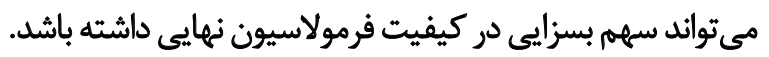

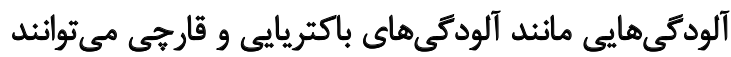

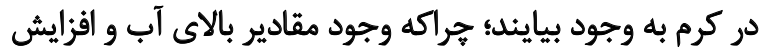
Water activity

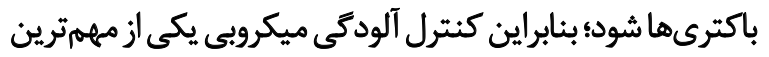

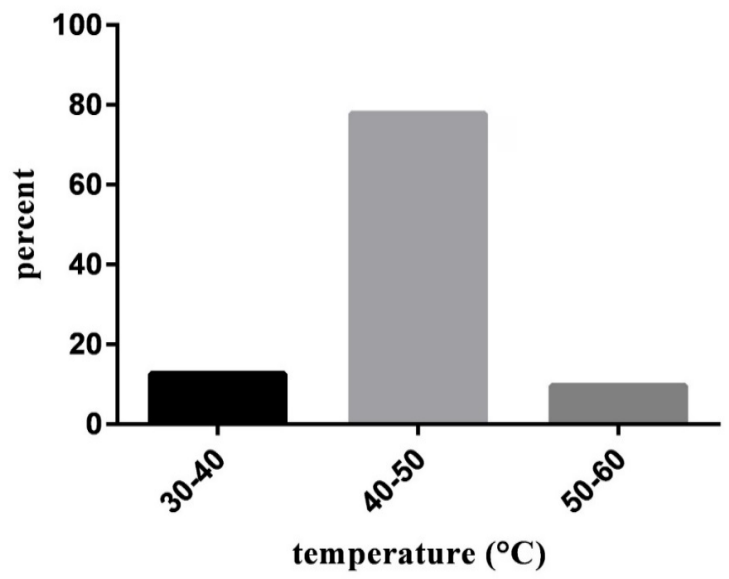

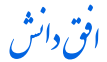

تصوير ا. توزيع فرواثى ميزان يايدارى فراوردههاي نيمهجامد تهيهشده از داروخائهاي سطح شهر يزد توند 


\section{amount of hydroquinone}

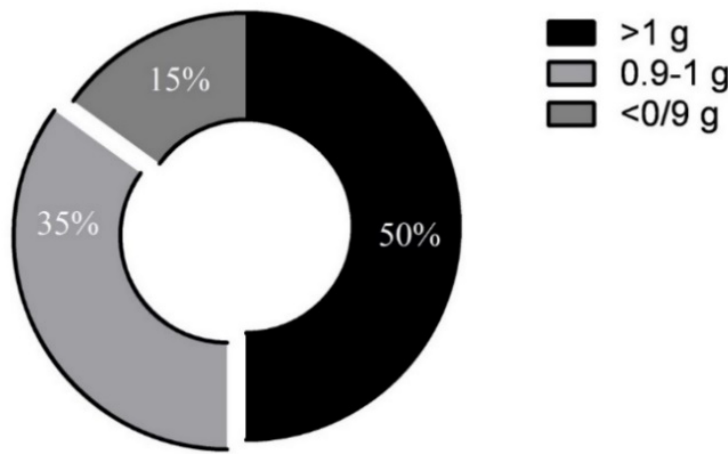

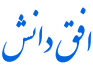

تصوير و. مقدار هيدروكينون موجود در فراوردههاى نيمهجامد تهيهشده از داروخانههاى سطح شهر يزد

جدول r. مقدار آلودكى ميكروبى مجاز از نظر فارماكويه آمريكا

\begin{tabular}{cccc}
\hline $\begin{array}{c}\text { Route of } \\
\text { Administration }\end{array}$ & $\begin{array}{c}\text { Total Aerobic } \\
\text { Microbial count } \\
\text { (Cfu/g or cfu/ml) }\end{array}$ & $\begin{array}{c}\text { Total combined } \\
\text { Yeasts /Molds count } \\
\text { (Cfu/g or cfu/ml) }\end{array}$ & Specified \\
\hline $\begin{array}{c}\text { Transdermal } \\
\text { patches }\end{array}$ & $1 . r$ & 1.1 & $\begin{array}{c}\text { Absence of } \\
\text { Pseudomonas or } \\
\text { Staphylococcus }\end{array}$ \\
\hline
\end{tabular}

\section{أنتوراتث}

آلودكى ميكروبى در داروهاى ساختنى را به حداقل مىرساند؛

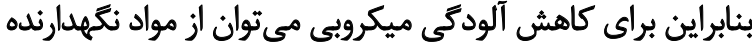

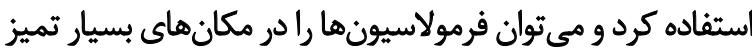

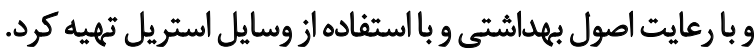

در مطالعهاى در انغلستان نيز ميكروب سودوموناس آئررينوزا

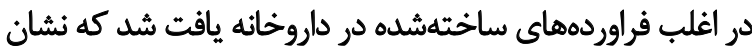

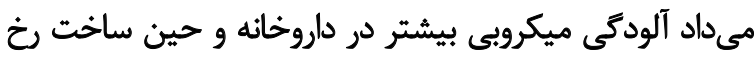

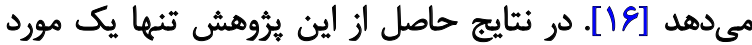

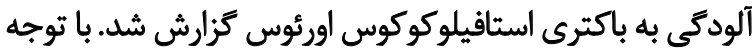

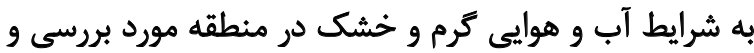

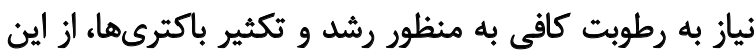

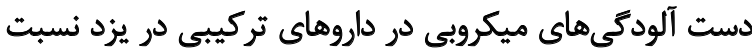

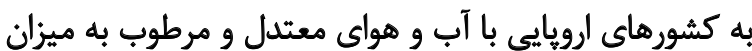

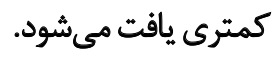

هيدروكينون ميتواند در محيط آبي در اثر كذشت زمان با باد

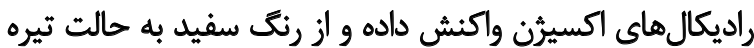

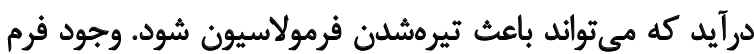

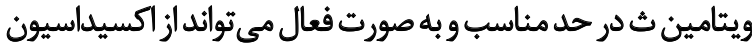

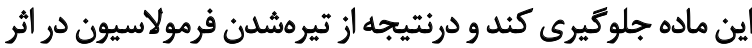

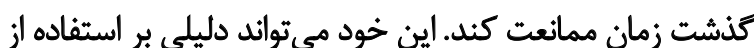

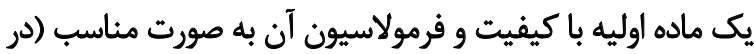

$$
\text { است كه اين فراوردهها مي توانئد داراى آلودگى باشند. }
$$

آلودگى ميكروبى مىتواند از مواد اوليه در حين ساخت و يا موقع

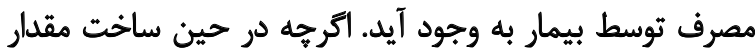

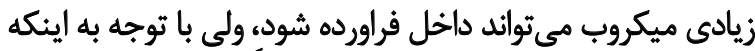

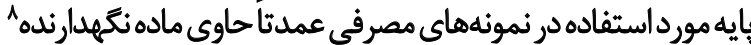

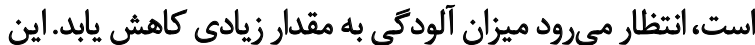

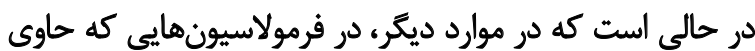

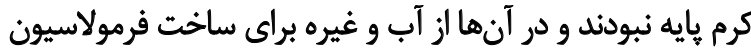

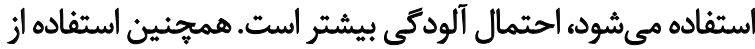

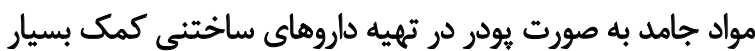

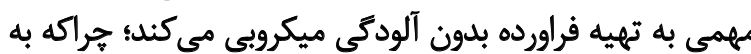

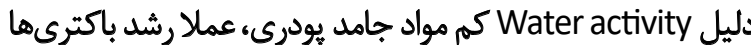
در آن كم است و فقط بعضى از باكترىها با بوانيانيى تشكيل اسيور مىثتوانتد در آنها وجود آنو داشته باشئد.

از طرفى عمده موادى كه در ساحت اين تركيب يا ديكر

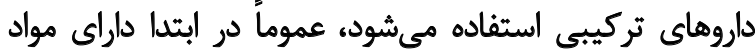

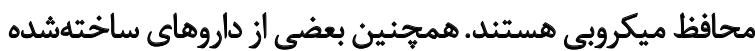

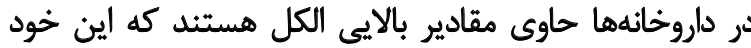
مى تواند باعث كاهش و توقف رشد ميكروبها شود كها واليى وجود

8. Preservative 
باعث كاهش ويسكوزيته خواهد شد [·r] .

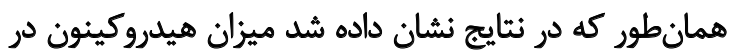

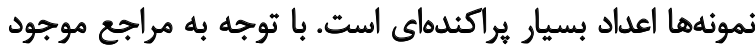

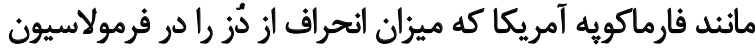

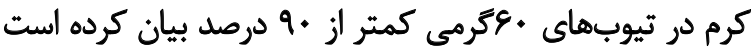

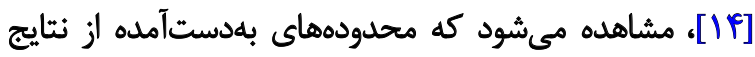

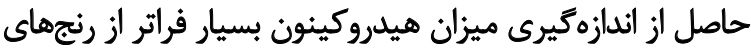

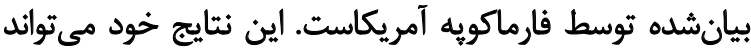

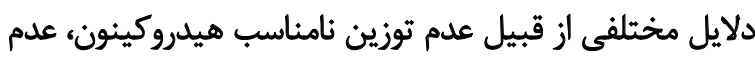

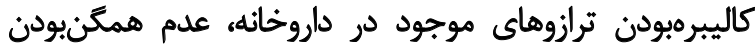

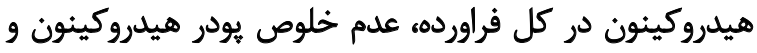

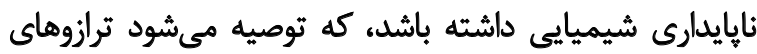

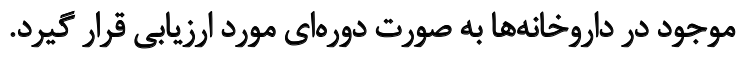

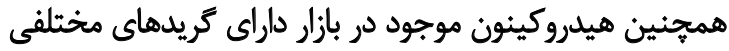

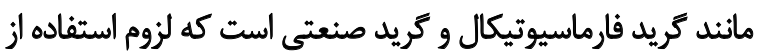

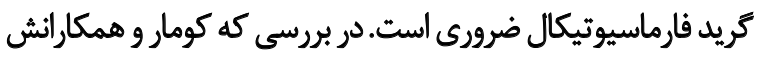

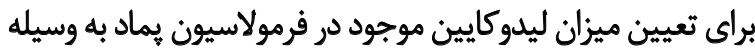

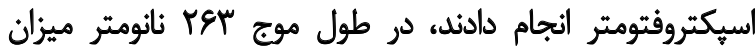

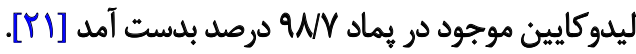

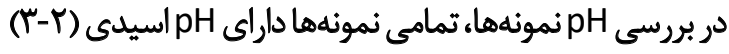

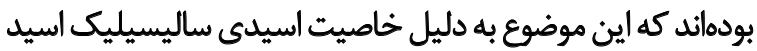

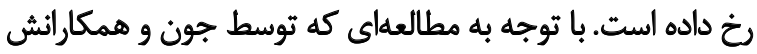

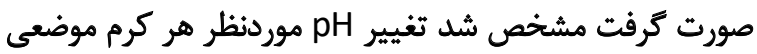

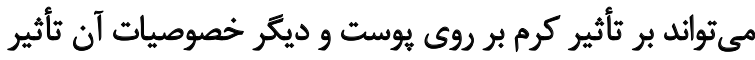

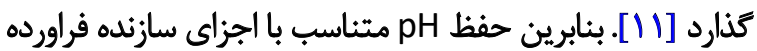
موضعى بر عملكرد مناسب آن تأثير كذار است.

\section{نتيجلئيرى}

با توجه به نتايج، عوامل متعددى نظير افرايش آكاهي،

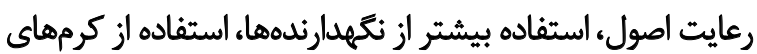

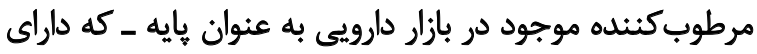

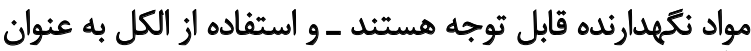

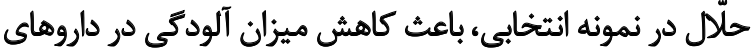

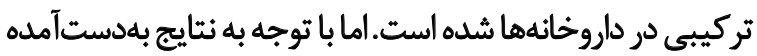

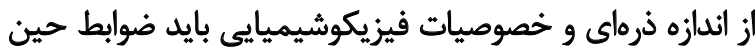

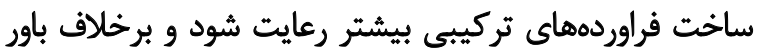

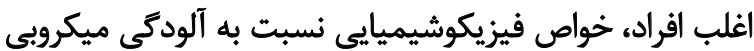
بايد مورد توجه بيشترى قرار كيرد.

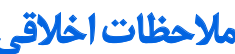

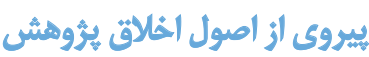
در اين يُروهش كليه قوانين مرتبط با تحقيقات دارويى رعايت
فاز آبي كرم) باشد. هرجند با توجه به مقالهاى كه ورماو همكارانش

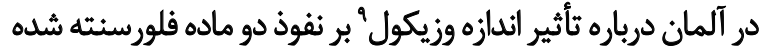

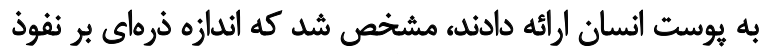

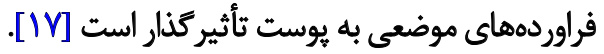

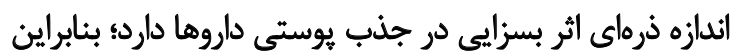

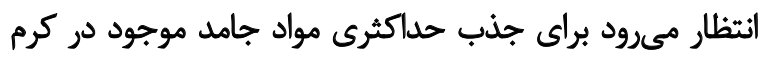

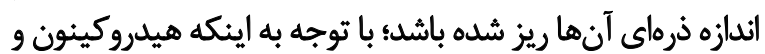

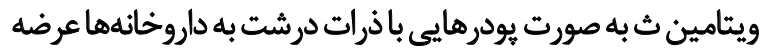

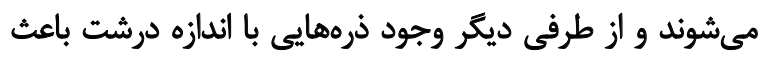

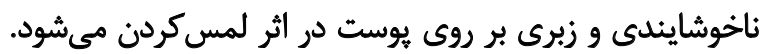

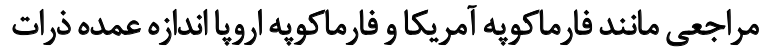

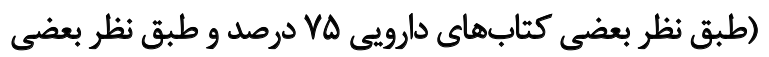

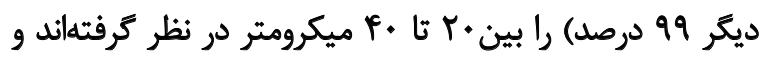

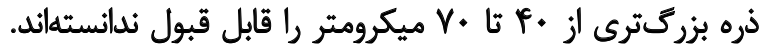

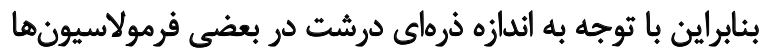

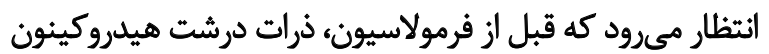

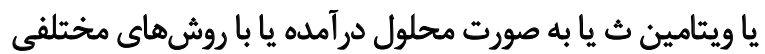

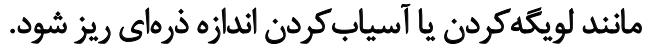
ويسكوزيته يكى از فاكتورهايى است كه براى استفاده راحت

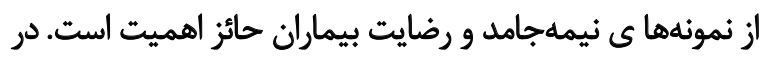

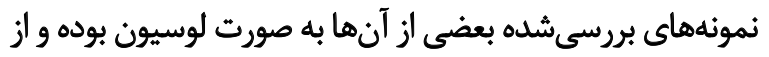

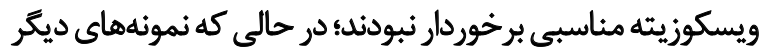
ويسكوزيته مناسبى داشتهاند. از آنجايى كه در فارماكويه آمريكا محدوده خاصى براى

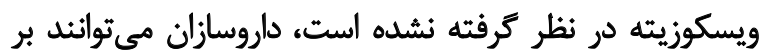

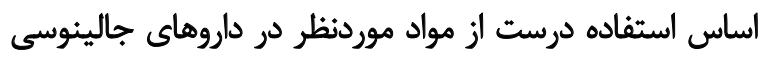

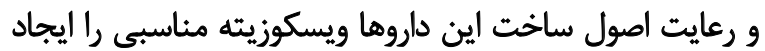

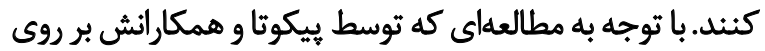

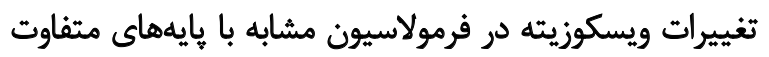

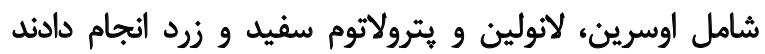
مشخص شده است عواملى مانئد بإيه مورداستفاده (اوسرين، يماد، كلد كرم و غيره) بر روى ويسكوزيته مواد مؤثرئد و هرجيه

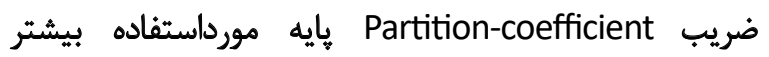

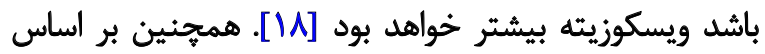

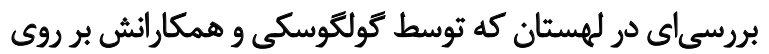

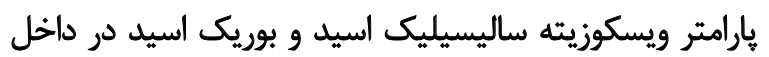
فرمولاسيون يماد صورت كرفت مشخص شيك شديك كه فرمولاسيون

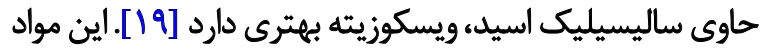

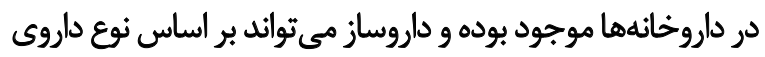

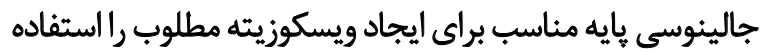

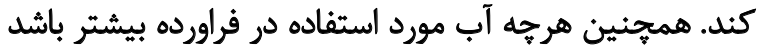




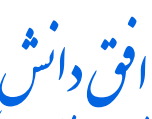

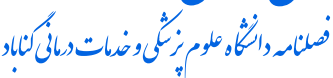

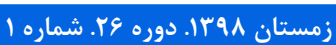

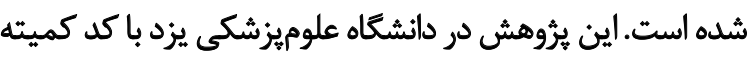

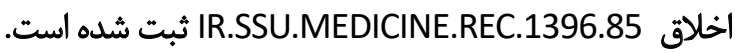

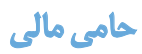

مثابع مالى اين يُؤهش از طريق معاونت يُوزهشى دانشكاه علوميزشكى يزد و كرنت يُروهشى استادان و دانشجو تأمين شد.

مشاركت نويسندكان

ايده اصلى، طراحى مطالعه، تدوين دستنوشته، بازبينى نهايى رئي

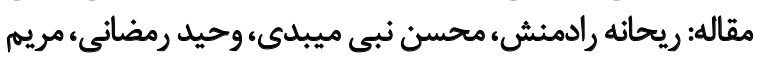
اكرمى، على محمد رنجبر و آزاده امامى.

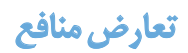

بنابر اظهار نويسندكان اين مقاله هيجكونه تعارض

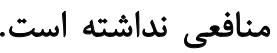

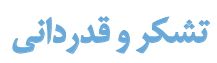

از جناب آقاى دكتر امير مسعود حيدرىنئراد و همجينين كليه

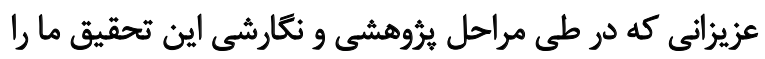
يارى كردند، صميمانه سياستَزارى مي كنيهم.

ريحاثه رادمنش و همكاران. بررسى خصوصيات فيزيكوشيمياييى وألودئى ميكروبى داروهاى ثركيبي

ar 


\section{References}

[1] Gholami Kh, Akbarzadeh T, Niknam S, Goodarzi N, Kaviani F, Kouti L, et al. Pharmaceutical Compounding. Teimourzadeh Poblication. 2014. http://opac.nlai.ir/opac-prod/bibliographic/3222076

[2] Ueda CT, Shah VP, Derdzinski K, Ewing G, Flynn G, Maibach H, et al. Topical and transdermal drug products. Pharmacopeial Forum; 2009; 35(3):750-64. https://pdfs.semanticscholar.org/fe79/2b44c22f6df0084 c5d643e6c90277f4a633f.pdf

[3] Bloomfield SF. Microbial contamination: Spoilage and hazard. In: Denyer SP, Baird RM, editors. Guide to Microbiological Control in Pharmaceuticals and Medical Devices. Boca Raton, FL: CRC Press; 2006. p. 23-50. [DOI:10.1201/9781420021622.ch2]

[4] Williams PG. Panning for chemical gold: Marine bacteria as a source of new therapeutics. Trends in Biotechnology. 2009; 27(1):45-52. [DOI:10.1016/j.tibtech.2008.10.005] [PMID]

[5] Larsson DJ. Pollution from drug manufacturing: Review and perspectives. Philosophical Transactions of the Royal Society B. 2014; 369(1656):20130571. [DOI:10.1098/rstb.2013.0571] [PMID] [PMCID]

[6] Riederer A, Grein G, Bogner J. High prevalence of opportunistic infections in the head and neck related to human immunodeficiency virus. A prospective study of the distribution of otorhinolaryngologic disorders in 250 patients. Infection. 1996; 24(6):440-6. [DOI:10.1007/ BF01713046] [PMID]

[7] Rosas, Juan G., Marcel Blanco, Josep M. González, and Manel Alcalá. "Quality by design approach of a pharmaceutical gel manufacturing process, part 1: Determination of the design space". Journal of Pharmaceutical Sciences. 2011; 10:4432-41. [DOI:10.1002/jps.22611] [PMID]

[8] Murray-Smith RJ, Coombe VT, Grönlund MH, Waern F, Baird JA. Managing emissions of active pharmaceutical ingredients from manufacturing facilities: An environmental quality standard approach. Integrated Environmental Assessment and Management. 2012; 8(2):320-30. [DOI:10.1002/ieam.1268] [PMID]

[9] Chang RK, Raw A, Lionberger R, Yu L. Generic development of topical dermatologic products: Formulation development, process development, and testing of topical dermatologic products. The AAPS journal. 2013; 15(1):41-52. [DOI:10.1208/s12248-012-9411-0] [PMID] [PMCID]

[10] Moghadam H, Samimi M, Samimi A, Khoram M. Study of parameters affecting size distribution of beads produced from electro-spray of high viscous liquids. Iranian Journal of Chemical Engineering. 2009; 6(3):88-98. https://iranjournals.nlai.ir/1294/article 341946 fabf2ca1e567a94cf2b837e7874ec7e7.pdf

[11] Jeon JS, Kim BH, Lee SH, Kwon HJ, Bae HJ, Kim SK, et al. Simultaneous determination of arbutin and its decomposed product hydroquinone in whitening creams using high-performance liquid chromatography with photodiode array detection: Effect of temperature and $\mathrm{pH}$ on decomposition. International Journal of Cosmetic Science. 2015; 37(6):567-73. [DOI:10.1111/ics.12228] [PMID]

[12] Behravan J, Fazly Bazzaz, Malaekeh P. Survey of bacteriological contamination of cosmetic creams in Iran (2000). International Journal of Dermatology. 2005; 44(6):482-5. [DOI:10.1111/j.13654632.2005.01963.x] [PMID]

[13] Gregory R, Edzwald J. Sedimentation and flotation. In: Edzwald JK editor. Water Quality \& Treatment: A Handbook on Drinking Water. $6^{\text {th }}$ ed. New York City: McGraw Hill Professional; 2010.

[14] Elmorsy T, Hafez E. Microbial contamination of some cosmetic preparations in Egypt. International Journal of Agricultural Technology. 2016; 12(3):567-77.
[15] Skowron K, Jakubicz A, Budzyńska A, Kaczmarek A, Grudlewska K, Reśliński $A$, et al. Microbiological purity assessment of cosmetics used by one and several persons and cosmetics after their expiry date. Roczniki Panstwowego Zakladu Higieny. 2017; 68(2):191-7.

[16] Jarvis B, Reynolds AJ, Rhodes AC, Armstrong M. A survey of microbiological contamination in cosmetics and toiletries in the UK 97. Journal of the Society of Cosmetic Chemists. 1974; 25(10):563-75.

[17] Verma DD, Verma S, Blume G, Fahr A. Particle size of liposomes influences dermal delivery of substances into skin. International Journal of Pharmaceutics. 2003; 258(1-2):141-51 [DOI:10.1016/S0378 5173(03)00183-2]

[18] Piechota-Urbanska M, Kolodziejska J, Zgoda MM. Viscosity of pharmacopeial multimolecular ointment vehicles and pharmaceutical availability of a model therapeutic agent. Polymers in Medicine. 2007; 37(2):3.

[19] Glogowski A, Kolodziejska J, Kolodziejczyk MK, Zgoda MM. The influence of the viscosity of the ointment vehicles magisterial topical preparations, on the speed transfer of biologically active substances. Current Issues in Pharmacy and Medical Sciences. 2015; 28(3):212-8 [DOI:10.1515/cipms-2015-0075]

[20] Bhargava S, Cooper SL. Effect of water on viscosity and shear-thickening behavior of telechelic ionomers in nonpolar solvents. Macromolecules. 1998; 31(2):508-14. [DOI:10.1021/ma970889c]

[21] Kumar BK, Rajan T, Begum NT. Analytical method development and validation of lidocaine in ointment formulation by $\mathrm{U}$. $\mathrm{V}$ spectrophotometric method. International Journal of Pharmacy and Pharmaceutical Sciences. 2012; 4(2):610-4. 